DISTRIBUTION STATEMENT A. Approved for public release; distribution is unlimited.

\title{
The Metabolic Cost of Click Production in Bottlenose Dolphins
}

\author{
Marla M. Holt and Dawn P. Noren \\ NOAA NMFS Northwest Fisheries Science Center \\ 2725 Montlake Blvd. East \\ Seattle, WA 98112 \\ phone: (206) 860-3261 fax: (206) 860-3475 email: marla.holt@noaa.gov \\ phone: (206) 302-2439 fax:(206) 860-3475 email: dawn.noren@noaa.gov
}

Terrie M. Williams

Center for Ocean Health, University of California, Santa Cruz

100 Shaffer Road

Santa Cruz, CA 95060

phone: (831) 459-5123 fax: (831) 459-3383 email: williams@biology.ucsc.edu

Award Numbers: N0001413IP20035 / N0001413IP20017 / N0001412IP20072 / N000141210270

http://www.nwfsc.noaa.gov/research/divisions/cbd/marine_mammal/marinemammal.cfm

\section{LONG-TERM GOALS}

Animals often increase the amplitude (the Lombard effect), duration, and/or repetition rate of their acoustic signals as a strategy to help reduce the probability of masking from environmental sounds (NRC 2003). Although accumulating evidence from recent research (Scheifele et al. 2005, Holt et al. 2009, Parks et al. 2010) illustrates that several marine mammal species readily modify the parameters of their acoustic signals to compensate for masking noise, potential energetic costs of such compensation behavior are unknown. To date, the only empirical data on the metabolic cost of sound production as well as the metabolic cost of increasing the amplitude of acoustic signals for any marine mammal species has been collected by the PIs during previously ONR-supported studies. The focus of the previous work was on communicative sound production in bottlenose dolphins (Holt et al. 2011 a, b; Noren et al. 2011, 2013). There is currently no information on energy expenditure during click production in odontocetes, and studies have demonstrated that they also readily modify these sound types in an echolocation context to compensate for masking noise. Given that changes in vocal behavior in response to masking noise has been documented in several species, assessing the biological significance of these effects is paramount but also very difficult given the life histories of marine mammals. The Population Consequences of Acoustic Disturbance (PCAD) model has been proposed as a framework to address this challenging task (NRC 2005). Data on the energetic cost of the production of clicks from this study can be used to assess the biological significance of vocal compensation in response to sound exposure and populate transfer function 2 (transfer function between behavior change to life functions immediately affected) in the PCAD model.

\section{OBJECTIVES}

The objective of this study was to measure oxygen consumption in two captive bottlenose dolphins to determine the metabolic cost of click production. The metabolic cost of click production was also 


\section{Report Documentation Page}

Form Approved

OMB No. 0704-0188

Public reporting burden for the collection of information is estimated to average 1 hour per response, including the time for reviewing instructions, searching existing data sources, gathering and maintaining the data needed, and completing and reviewing the collection of information. Send comments regarding this burden estimate or any other aspect of this collection of information,

including suggestions for reducing this burden, to Washington Headquarters Services, Directorate for Information Operations and Reports, 1215 Jefferson Davis Highway, Suite 1204, Arlington

VA 22202-4302. Respondents should be aware that notwithstanding any other provision of law, no person shall be subject to a penalty for failing to comply with a collection of information if it

does not display a currently valid OMB control number.

1. REPORT DATE

30 SEP 2014

4. TITLE AND SUBTITLE

The Metabolic Cost of Click Production in Bottlenose Dolphins

6. $\operatorname{AUTHOR}(\mathrm{S})$

7. PERFORMING ORGANIZATION NAME(S) AND ADDRESS(ES)

National Oceanic and Atmospheric Administration (NOAA), NMFS

Northwest Fisheries Science Center,2725 Montlake Blvd.

East,Seattle,WA,98112

9. SPONSORING/MONITORING AGENCY NAME(S) AND ADDRESS(ES)
3. DATES COVERED

00-00-2014 to 00-00-2014

5a. CONTRACT NUMBER

5b. GRANT NUMBER

5c. PROGRAM ELEMENT NUMBER

5d. PROJECT NUMBER

5e. TASK NUMBER

5f. WORK UNIT NUMBER

8. PERFORMING ORGANIZATION

REPORT NUMBER

10. SPONSOR/MONITOR'S ACRONYM(S)

11. SPONSOR/MONITOR'S REPORT NUMBER(S)

12. DISTRIBUTION/AVAILABILITY STATEMENT

Approved for public release; distribution unlimited

13. SUPPLEMENTARY NOTES

14. ABSTRACT

15. SUBJECT TERMS

16. SECURITY CLASSIFICATION OF:

a. REPORT

unclassified b. ABSTRACT

unclassified c. THIS PAGE

unclassified
17. LIMITATION OF ABSTRACT

Same as

Report (SAR)
18. NUMBER 19a. NAME OF OF PAGES

15 RESPONSIBLE PERSON 
compared to resting metabolic rates, the metabolic cost of whistles and other communicative sound, and the metabolic costs of other activities, such as performing surface active behaviors (SABs) and/or swimming. This work required over two years to complete. Work during year 1 (2012) included training dolphins to perform the necessary behaviors and measuring metabolic rates during click production and control trials. The focus of year 2 (ending in December 2013) was to increase the number of click production trials and begin analyses to quantify the metabolic cost of click production. Data analysis continued through May 2014 with subsequent post-trial calibration of the instruments and metabolic baseline.

\section{APPROACH}

The metabolic cost of click production was measured in two captive male Atlantic bottlenose dolphins (Tursiops truncatus) maintained at Dr. Terrie Williams' Mammalian Physiology Laboratory at the University of California, Santa Cruz, Long Marine Laboratory. These individuals were trained by Traci Kendall (Program Manager/Research Training Supervisor) and Beau Richter (Head Trainer) to produce clicks on command while stationed under a metabolic hood to measure oxygen consumption. The sounds of free-ranging Atlantic bottlenose dolphins have been described as clicks, whistles, buzzes, quacks, and pops (Jacobs et al. 1993). The trained sounds of the captive dolphins of the current study are representative of those found in wild, free-ranging populations.

All metabolic trials were conducted in the morning after an overnight fast to eliminate the potential for the metabolic cost of digestion to confound oxygen consumption measurements. Thus, food was given after the dolphin completed the entire trial and only one trial was conducted per dolphin per day. Dissimilar to the previous study to determine the metabolic cost of communicative sound in which sound production occurred at the water surface (Noren et al. 2011, 2013), the dolphins produced clicks more consistently while under water (which is more typical of echolocating individuals in their natural environment). Thus, data were collected while the dolphins were submerged during click production (they remained at the water surface during baseline, the $15 \mathrm{sec}$ break between click bouts, and recovery). Briefly, each click production trial consisted of three consecutive periods in which one dolphin entered the metabolic hood (details described in next paragraph) for (1) a 10-minute period of baseline rest when the dolphin remained still and quiet at the water surface (to determine baseline metabolic rate), followed by (2) a click period with minimal body movement, consisting of two consecutive one-min bouts of clicks performed (as cued by the trainer) completely submerged just below the water surface separated by $15 \mathrm{sec}$ of silence at the water surface, and concluded with (3) a recovery period when the dolphin again remained still and quiet at the water surface (for at least 10 minutes, or until oxygen consumption values appeared to return to baseline resting values). Because of the modification of the experimental protocol relative to the approach used for measuring the cost of communicative sound production, control trials in which the animals did not produce sound were also run in a manner that mimicked the total trial duration and submergence pattern of click production trials. The total duration of control trials were $22 \mathrm{~min} 15 \mathrm{sec}$ and were identical to click production trials, except for the second of the three consecutive periods. During control trials, the second period consisted of the dolphin remaining silent during two one-min periods below the water surface that were separated by $15 \mathrm{sec}$ of silence at the water surface. Control trials were conducted in this manner to provide data to quantify the reduction in metabolic rate during submergence and the concomitant increase in metabolic rate upon surfacing so that the metabolic cost of click production could be isolated from click trials. 
During all click production trials, the dolphins were acoustically monitored in real-time and their sounds were recorded for further analysis as described below. The total durations of the baseline period, click period, and recovery period were recorded for each click production trial. Respirations were also recorded during each of the three periods so that respiration rates could be calculated for the dolphins during baseline rest, click production, and recovery. The dolphin's behavior during each click production trial was also video recorded to ensure that body movement was kept to a minimum during all trial periods (baseline rest, click period, recovery). As mentioned above, separate control trials were also conducted to measure oxygen consumption and respiration rates in the absence of click production. See figure 1 for a photograph taken during a sound production trial.

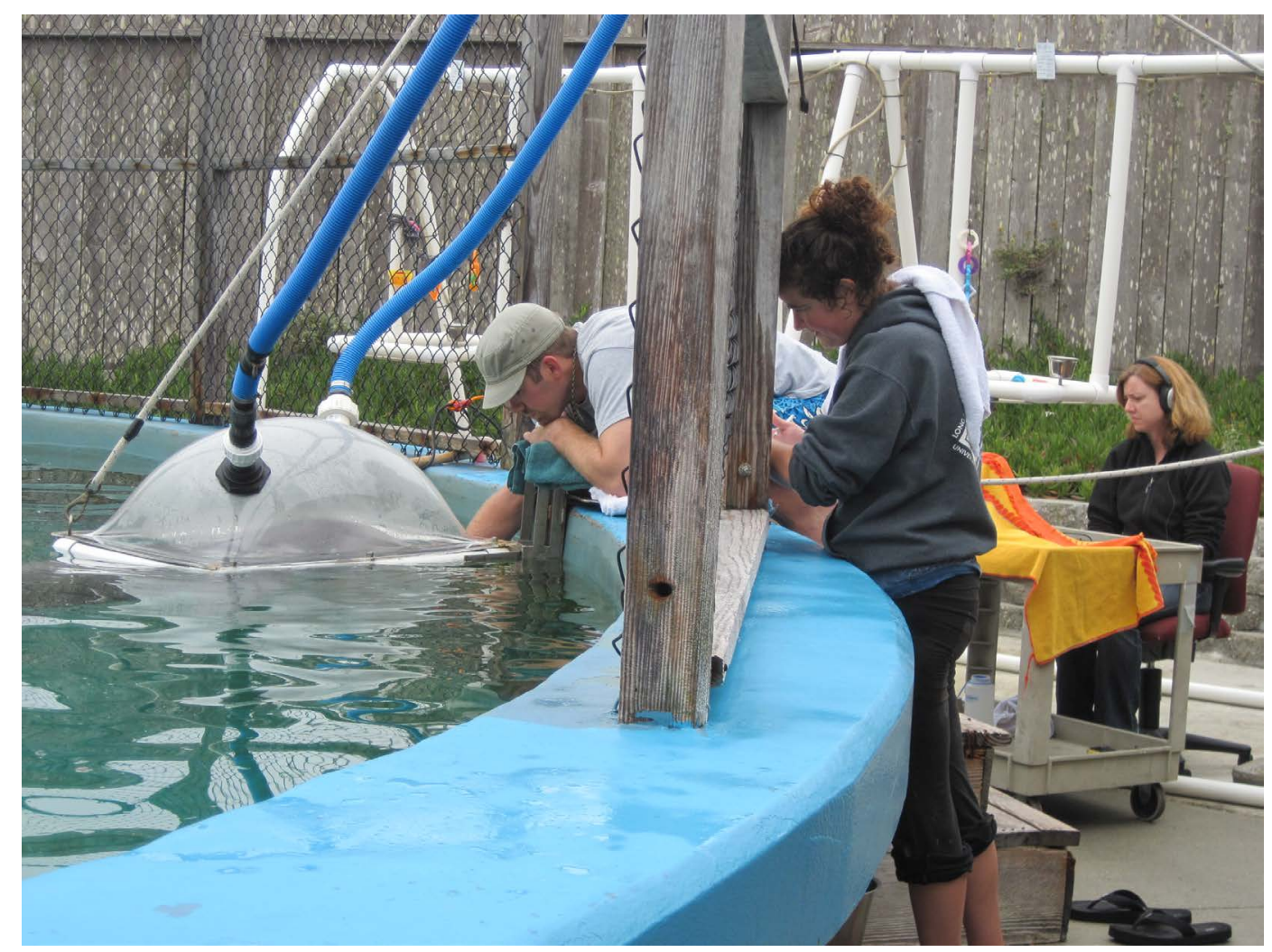

Figure 1. Photograph taken during a sound production trial showing the equipment set-up which includes the metabolic hood, the dolphin stationed under the metabolic hood, the acoustic recording equipment and operator, the dolphin trainer, and the assistant taking notes and recording respirations. During the trial dolphin clicks were recorded via a hydrophone attached to the melon by suction cup (not shown), oxygen consumption was continuously logged by an $\mathrm{O}_{2}$ analyzer attached to a computer, and all respirations were recorded during each of the three periods.

With the exception of dolphins producing sounds underwater in the present study, the method used to determine metabolic rates from oxygen consumption values is similar to those used previously on bottlenose dolphins producing communicative sounds (Noren et al. 2011, 2013). For this study, the rate of oxygen consumption $\left(\dot{V}_{2}\right)$ was determined for quiescent dolphins stationed at the water surface and for the same dolphins producing clicks near the water surface. Air was drawn into the hood at a flow rate of $300 \mathrm{~L} \mathrm{~min}^{-1}$. The flow rate was maintained such that the content of oxygen in the hood remained above $20 \%$. Water and $\mathrm{CO}_{2}$ from subsamples of excurrent air from the hood were absorbed 
using Drierite and Baralyme, respectively, prior to entering the oxygen analyzer. The percentage of oxygen in the sample line was monitored continuously (FMS field metabolic rate system, Sable Systems International) and recorded by a laptop computer every second during click production and control trials. $\dot{V}_{\mathrm{O}_{2}}$ for silent and clicking dolphins were calculated from the percentage oxygen data by respirometry software (Expedata data acquisition and analysis software, Sable Systems International). Data were adjusted for the lag time of the system prior to determining $\dot{V}_{\mathrm{O}_{2}}$ for each of the trial components. For each experimental trial, "baseline RMR" was calculated by averaging $\dot{V}_{\mathrm{O}_{2}}$ during the most level 5 min (determined by the "level" function in Expedata) of the last 8 min of the baseline resting period. The first two minutes of the baseline period were excluded to eliminate the period in which the dolphin's metabolic rate is elevated after swimming into the metabolic hood. Metabolic rate (MR) during the 2.25 min submerged clicks bout and MR during the 2.25 min submerged silence bout were both calculated by averaging $\dot{V}_{\mathrm{O}_{2}}$ from the beginning of the first click/silent submergence to the end of the second click/silent submergence. Average MR during the first 2 min of the recovery period (hereafter referred to as the " 2 min post submergence") was also calculated for comparison.

"Recovered MR" was calculated by averaging $\dot{V}_{\mathrm{O}_{2}}$ during the most level $5 \mathrm{~min}$ (determined by the "level" function in Expedata) of the recovery period. Finally, for each dolphin the metabolic cost of click production above submerged resting cost was estimated by subtracting the average metabolic cost of the 2.25 min submerged silence bout recorded during control trials from the metabolic cost of the 2.25 min submerged clicking bout recorded during click production trails. Dr. Dawn Noren in collaboration with Dr. Robin Dunkin (post-doc) were responsible for collecting and analyzing the respiration rate and oxygen consumption data.

All click production trials were acoustically monitored in real-time by both the dolphin trainer and an experimenter and also recorded using calibrated equipment. A contact hydrophone was placed on the dolphin's melon during trials to carefully quantify a variety of click parameters to compare click performance across trials. This method was used because the dolphin was stationed at or close to the water surface under the hood and small changes in dolphin position can affect how much sound energy is transmitted under water. The contact hydrophone consisted of a Reson TC 4013 hydrophone that was molded into a small suction cup for contact. The contact hydrophone was then connected through a bandpass filter and amplified (Reson VP 2000), and the signal was sent through a DAQ device (IOTech Personal DAQ 3000) which digitized the signal at a sampling rate of $500 \mathrm{kHz}$. The sound files were stored on a PC laptop for further analysis. The contact hydrophone was placed at the same location on the melon of the dolphin for each trial and remained in the same position during all trial periods (baseline rest, click production, and recovery). For the click period of each trial, the approximate start time of each click in the corresponding sound file was determined using Avisoft SASlab Pro (v5.2.07) pulse train analysis feature. The received peak-to-peak sound pressure level (dB re: $1 \mu \mathrm{Pa} \mathrm{pp}$ ), duration (in $\mu \mathrm{sec}$ ), inter-click interval (in msec), and received energy flux density level (dB re: $1 \mu \mathrm{Pa}^{2}$ s, also known as sound exposure level) of each click along with the cumulative energy of all clicks per trial were then determined using custom written routines in MATLAB (R2011b or higher versions, MathWorks). The received energy flux density level of each click was based on the $95 \%$ accumulated energy content of each click waveform and the duration was defined as the time window that corresponding to 95\% of accumulated energy (Madsen and Wahlberg, 2007). Dr. Marla Holt was responsible for collecting and analyzing the acoustic data. 


\section{WORK COMPLETED}

A total of ten trips to Dr. Terrie Williams' Mammalian Physiology Laboratory at the University of California, Santa Cruz, Long Marine Laboratory were completed for the project. The first three trips were conducted to finalize study design, tackle technical issues, and evaluate the dolphins' clicking behavior during practice trials. The later week-long trips were conducted June 2012 through February 2013 to collect data for potential inclusion in the results. During these later trips, click production trials were run on 5 consecutive days for a total of 35 click production trials per dolphin. Control trials were also conducted 2-3 times per month between mid-June 2012 and early March 2013, resulting in 27 control trials per dolphin. Because resting metabolic rates vary monthly (Williams and Dunkin, unpublished data), we discarded results from control trials conducted during months in which no click production trials were conducted. Some of the click production trials were not included in the analysis because of inconsistent click performance or other experimental issues. Statistical and graphical analyses are complete and the results are included in this report. Results were deemed significant at $\mathrm{P}$ $<0.05$.

During 2014 final metabolic baseline data on the test dolphins was completed to account for potential seasonal variation and metabolic drift. In addition, post-trial oxygen analyzer calibration was completed to enable finalization of metabolic statistics for publication of the results. Manuscripts are currently in review.

\section{RESULTS}

For Primo (Dolphin A), a total of 17 control and 25 click production trials were included in the analysis. A total of 19 and 29 control and click production trials, respectively, from Puka (Dolphin B) were included in the analysis. Example spectrograms of the clicks produced by each dolphin during click production trials are shown in Fig. 2. Click production parameters reported as means across all trials are summarized in Table I. Not surprisingly, the inter-click interval was strongly negatively correlated with the number of clicks produced on a per trial basis in both dolphins. There was also a significant negative relationship between the number of clicks produced and the received sound pressure level ( $\mathrm{dB}$ re $1 \mu \mathrm{Pa} \mathrm{pp}$ ) and the received sound pressure level and click duration in both dolphins, although the effects were more pronounced in Dolphin A. On average, Dolphin B produced clicks with higher sound pressure levels ( $\mathrm{dB}$ re $1 \mu \mathrm{Pa}$ pp) and energy flux density levels with less variability among trials than Dolphin A (Table I). Across trials, the difference between the minimum and maximum value of the click cumulative energy flux density level on a per trial basis was $8.0 \mathrm{~dB}$ re $1 \mu \mathrm{Pa}^{2} \mathrm{~s}$ in Dolphin B compared to $20.5 \mathrm{~dB}$ re $1 \mu \mathrm{Pa}^{2} \mathrm{~s}$ in Dolphin A. Assuming that the received levels recorded from the submerged contact hydrophone on the melon are close to but slightly below the true free-field source levels by a few dB (Au et al. 1978), only Dolphin B's sound pressure (peakto-peak) and energy flux density levels are within the range of echolocating wild bottlenose dolphins, albeit at the lower end (Wahlberg et al. 2011). Dolphin A's peak-to-peak sound pressure levels are more consistent with values reported for bottlenose dolphins performing echolocation tasks in tanks (for review, see Au 1993). 

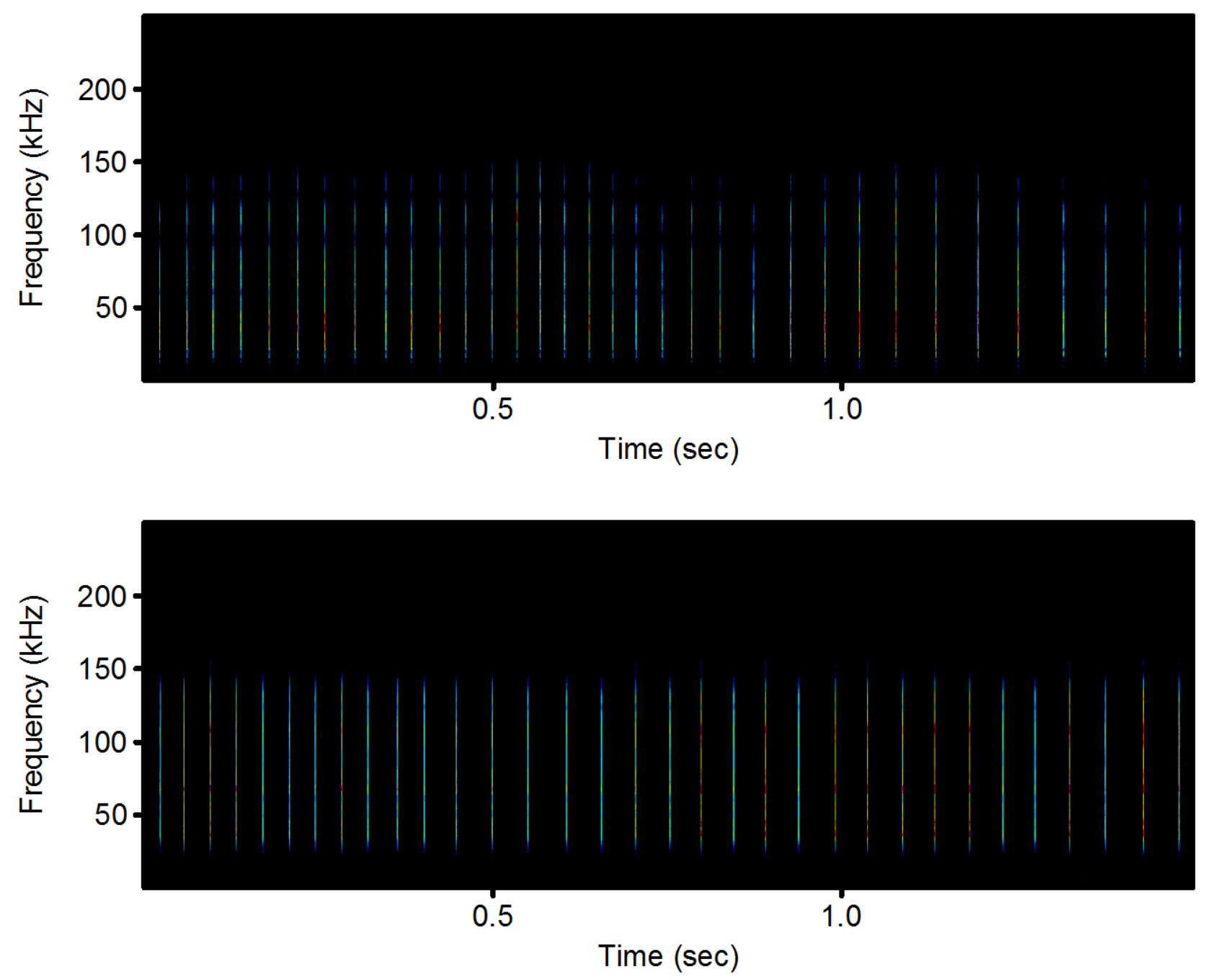

Figure 2. Spectrograms showing 1.5 second examples of clicks performed by Dolphin A (top panel) and Dolphin B (bottom panel) as recorded by a contact hydrophone place on the melon of the

dolphin. Both spectrograms show visual representations of clicks produced during oxygen consumption data collection with time from 0-1.5 seconds on the $x$-axis and frequency from 0-250 $\mathrm{kHz}$ on the $y$-axis.

The colors denote relative level or amplitude differences with red indicating higher levels and blue indicating lower levels.

Table I. Acoustic parameters of click production reported as means \pm 1 s.d. across all click production trials for each dolphin.

\begin{tabular}{|c|c|c|c|c|c|c|c|}
\hline Subject & $\begin{array}{c}\text { No. } \\
\text { of } \\
\text { trials }\end{array}$ & $\begin{array}{l}\text { No. of } \\
\text { clicks } \\
\text { produced } \\
\text { per trial }\end{array}$ & $\begin{array}{c}\text { Click } \\
\text { duration } \\
(\mu s)\end{array}$ & $\begin{array}{c}\text { Inter-click } \\
\text { interval } \\
(\mathrm{ms})\end{array}$ & $\begin{array}{l}\text { Received } \\
\text { sound } \\
\text { pressure } \\
\text { level } \\
\text { (dB re } 1 \\
\mu \mathrm{Pa} \mathrm{pp} \text { ) }\end{array}$ & $\begin{array}{c}\text { Mean } \\
\text { energy flux } \\
\text { density of } \\
\text { each click } \\
\left(\mathrm{dB}^{2} \mathrm{re} 1\right. \\
\left.\mu \mathrm{Pa}^{2} \mathrm{~s}\right)\end{array}$ & $\begin{array}{l}\text { Cumulative } \\
\text { energy flux } \\
\text { density of all } \\
\text { clicks per trial } \\
\text { (dB re } 1 \mu \mathrm{Pa}^{2} \text { s) }\end{array}$ \\
\hline A & 25 & $3978 \pm 842$ & $84.7 \pm 14.9$ & $32.8 \pm 8.7$ & $169.0 \pm 5.2$ & $117.7 \pm 5.5$ & $153.6 \pm 4.9$ \\
\hline $\mathrm{B}$ & 29 & $3406 \pm 950$ & $50.4 \pm 9.8$ & $38.5 \pm 11.9$ & $180.0 \pm 2.7$ & $124.3 \pm 2.6$ & $159.5 \pm 2.3$ \\
\hline
\end{tabular}


Metabolic and respiration rates reported as means across components of the two trial types (control and click production) are summarized in Tables II and III, respectively. The metabolic and respiratory response to submergence and click production were similar for the two dolphins, though more marked in Dolphin A (Tables II, III and Figs. 3, 4, 5, 6). Not surprisingly, metabolic rates decreased $(\mathrm{P}<0.05)$ upon submergence during both trial types, in part because the animals only breathed a few times during the 15 second break between the two 1-min bouts of submerged clicks and submerged silence (Table III and Figs 5, 6), and also in part due to the dive response (Table II and Figs. 3A, 4A).

Table II. Mass-specific metabolic rates reported as means \pm 1 s.d. across components of both trial types for each dolphin.

\begin{tabular}{lcccccc}
\hline Subject & $\begin{array}{c}\text { Trial } \\
\text { Type }\end{array}$ & $\begin{array}{c}\text { No. } \\
\text { of } \\
\text { trials }\end{array}$ & $\begin{array}{c}\text { Baseline RMR } \\
\left(\mathrm{ml} \mathrm{O}_{2} \mathrm{~min}^{-1} \mathrm{~kg}^{-1}\right)\end{array}$ & $\begin{array}{c}2 \mathrm{~min} \text { submerged } \\
\mathrm{MR} \\
\left(\mathrm{ml} \mathrm{O}_{2} \mathrm{~min}^{-1} \mathrm{~kg}^{-1}\right)\end{array}$ & $\begin{array}{c}2 \text { min post } \\
\text { submerged } \\
\mathrm{MR}\end{array}$ & $\begin{array}{c}\text { Recovered MR } \\
\left(\mathrm{ml} \mathrm{O}_{2} \mathrm{~min}^{-1} \mathrm{~kg}^{-1}\right)\end{array}$ \\
\hline A & Control & 17 & $3.9 \pm 0.3$ & $2.4 \pm 0.7$ & $6.6 \pm 1.1$ & $4.4 \pm 0.4$ \\
B & Control & 19 & $4.2 \pm 0.4$ & $2.9 \pm 0.7$ & $4.7 \pm 0.7$ & $3.8 \pm 0.3$ \\
A & $\begin{array}{c}\text { Click } \\
\text { Product. }\end{array}$ & 25 & $4.0 \pm 0.3$ & $2.6 \pm 0.7$ & $6.7 \pm 0.5$ & $4.5 \pm 0.4$ \\
& $\begin{array}{c}\text { Click } \\
\text { B }\end{array}$ & 29 & $4.1 \pm 0.4$ & $3.2 \pm 0.6$ & $4.5 \pm 0.6$ & $4.1 \pm 0.5$ \\
\hline
\end{tabular}

Table III. Respiration rates reported as means \pm 1 s.d. across components of both trial types for each dolphin.

\begin{tabular}{|c|c|c|c|c|c|}
\hline Subject & $\begin{array}{l}\text { Trial } \\
\text { Type }\end{array}$ & $\begin{array}{l}\text { No. } \\
\text { of } \\
\text { trials }\end{array}$ & $\begin{array}{l}\text { Two min prior to } \\
\text { submergence RR } \\
\left(\text { breaths } \mathrm{min}^{-1} \text { ) }\right.\end{array}$ & $\begin{array}{l}2 \text { min submerged } \\
\text { RR (breaths min-1) }\end{array}$ & $\begin{array}{l}2 \text { min post submerged RR } \\
\text { (breaths } \min ^{-1} \text { ) }\end{array}$ \\
\hline A & Control & 17 & $4.9 \pm 1.4$ & $2.3 \pm 1.3$ & $6.5 \pm 1.7$ \\
\hline B & Control & 19 & $1.7 \pm 0.4$ & $1.0 \pm 0.4$ & $2.3 \pm 0.6$ \\
\hline A & $\begin{array}{c}\text { Click } \\
\text { Product. }\end{array}$ & 25 & $4.4 \pm 0.9$ & $2.2 \pm 0.9$ & $6.4 \pm 1.3$ \\
\hline B & $\begin{array}{c}\text { Click } \\
\text { Product. }\end{array}$ & 29 & $1.8 \pm 0.5$ & $1.4 \pm 0.5$ & $2.5 \pm 0.7$ \\
\hline
\end{tabular}

The significant increase $(\mathrm{P}<0.05)$ in metabolic rate above resting values during the 2 min post submergence period indicates that the dolphins had to increase metabolism to recover from the small oxygen debt incurred during submerged click production and submerged silence (Figs. 3A, 4A). Although metabolic rates during submerged click production tended to be greater than during submerged silence, these differences were not significant, indicating that the metabolic cost of clicking is very small (Table II, Figs. 3A, 4A). 
Because an individual's metabolic rate can vary daily due to physiological and external factors, the best approach to calculate the cost of submergence and clicking is to assess the change in metabolism, relative to baseline, for each individual trial. The results of this analysis are depicted in Figs. 3B and 4B. For both dolphins, the reduction in MR relative to baseline (indicated by a negative value) was less while clicking during submergence, compared to the reduction in MR during silent submergence. This indicates that there is a metabolic cost to click production. However, the difference in metabolic reduction during submergence between the control and click production trials was only significant for Dolphin B $(\mathrm{P}<0.05)$, likely reflecting the higher energy levels of the clicks produced by Dolphin $\mathrm{B}$ relative to Dolphin A (Table I). There was no significant difference in the increase in metabolic rate, relative to baseline (indicated by a positive value), during 2 min post submergence across the two trial types for either dolphin (Figs. 3B, 4B). Thus, the increased metabolic rate resulting from click production does not appear to extend beyond the period in which the dolphin is actively clicking. Dolphin B recovered completely from the metabolic costs associated with submergence and clicking by the end of the recovery period (Figs. 4A, B). In contrast, Dolphin A's metabolic rate remained slightly elevated $(\mathrm{P}<0.05)$ during the recovery period following both submerged clicking and silence (Figs. 3A, B). Because there was no significant difference in "recovered MR" across the two trial types, it is evident that the prolonged elevation in Dolphin A's metabolism was due to recovery from submergence, not click production.

The average metabolic cost of click production alone was estimated for each dolphin according to the following equation:

$\mathrm{MC}_{\text {click production }}=$ Bout duration * $\left(\right.$ Mean $\mathrm{MR}_{\text {submerged click period }}-$ Mean $\left.\mathrm{MR}_{\text {submerged silent period }}\right)$ Eq. 1

Where $\mathrm{MC}$ is metabolic cost in $\mathrm{ml} \mathrm{O}_{2}$, bout duration is $2.25 \mathrm{~min}$ and $\mathrm{MR}$ is metabolic rate in $\mathrm{ml} \mathrm{O}_{2}$ $\min ^{-1}$.

For Dolphin B, the isolated cost of producing clicks for 2.25 min with a 0.25 min break was $0.7 \mathrm{kcal}$ (equivalent to approximately 0.0014 herring or 0.030 capelin). The cost for Dolphin A was about half of this cost ( $0.4 \mathrm{kcal}$, equivalent to approximately 0.0008 herring or 0.017 capelin). The higher cost of producing clicks for Dolphin B is likely related to the higher energy levels of the clicks he produced, relative to Dolphin A (Table I).

Respiration rates mirrored metabolic rates during click production and control trials (Figs. 5, 6). Respiration rates were significantly $(\mathrm{P}<0.05)$ elevated during the period when Dolphin B clicked while submerged, relative to producing no sound while submerged (Fig. 6A). All of these results combined demonstrate that there is a small, but measurable metabolic cost to clicking during submergence, yet this cost is negligible in diving dolphins. 


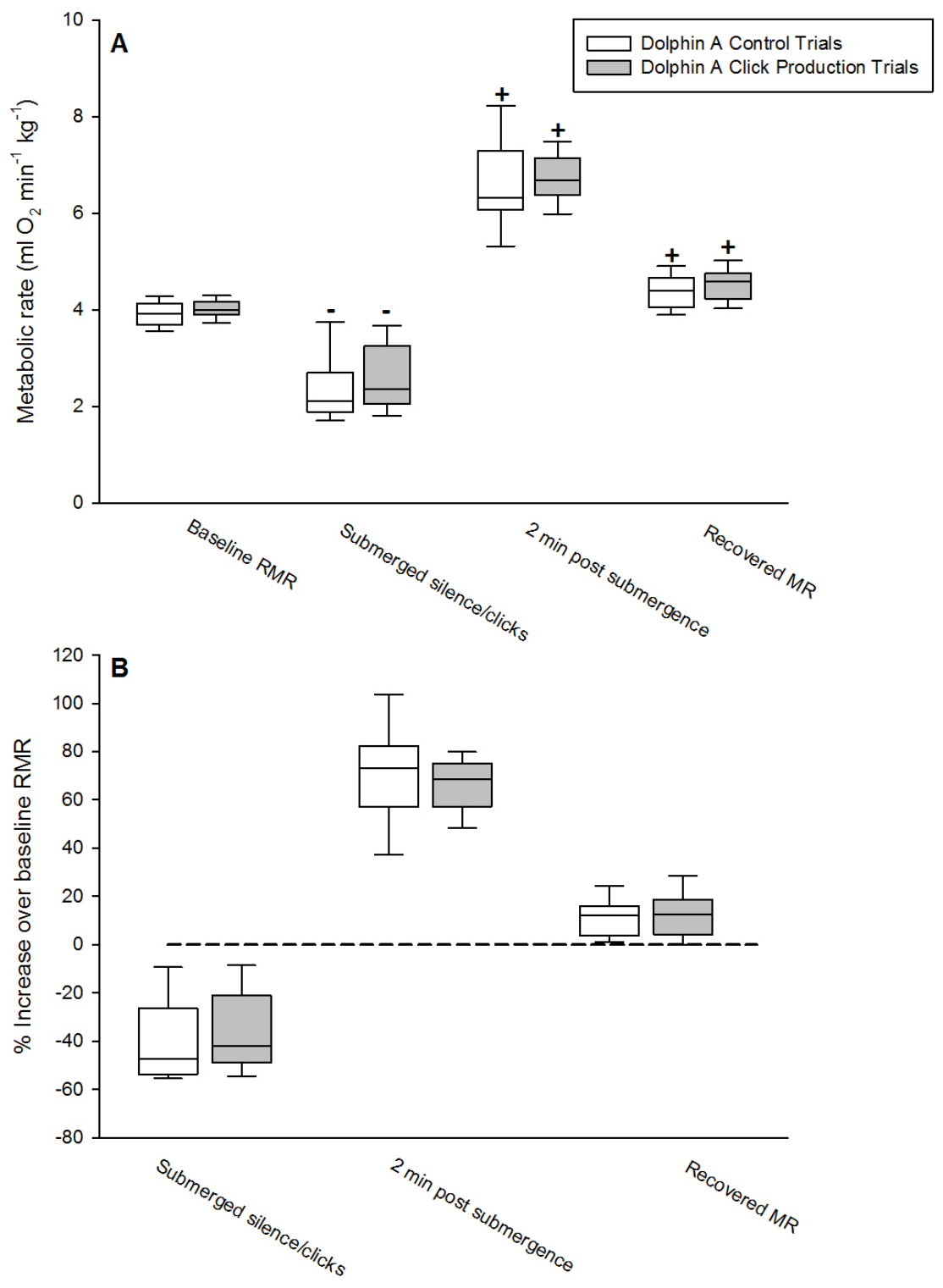

Figure 3. Metabolic rate (A) and percent increase over baseline metabolic rate (B) during components of control and click production trials for Dolphin $A$. Box plots are presented with white bars representing control (silent) trials and gray bars representing click production trials. For each box plot, the bottom of the box indicates the 25th percentile, the solid line within the box marks the median, and the top of the box indicates the 75th percentile. Error bars above and below the box indicate the 90th and 10th percentiles, respectively. The trial components are described in the methods. Metabolic rates that are significantly $(P<0.05)$ lower and higher than baseline values within the same trial type are indicated by - and + , respectively. Metabolic rates and percent increase over baseline RMR did not differ across trial type (click production or control) for any trial components. In figure $B$, the dashed line at 0 indicates no change in metabolic rate, relative to baseline. Negative values indicate that the metabolic rate recorded during a trial component was reduced, relative to the baseline value recorded during the same trial. Positive values indicate that the metabolic rate recorded during a trial component was increased, relative to the baseline value recorded during the same trial. 

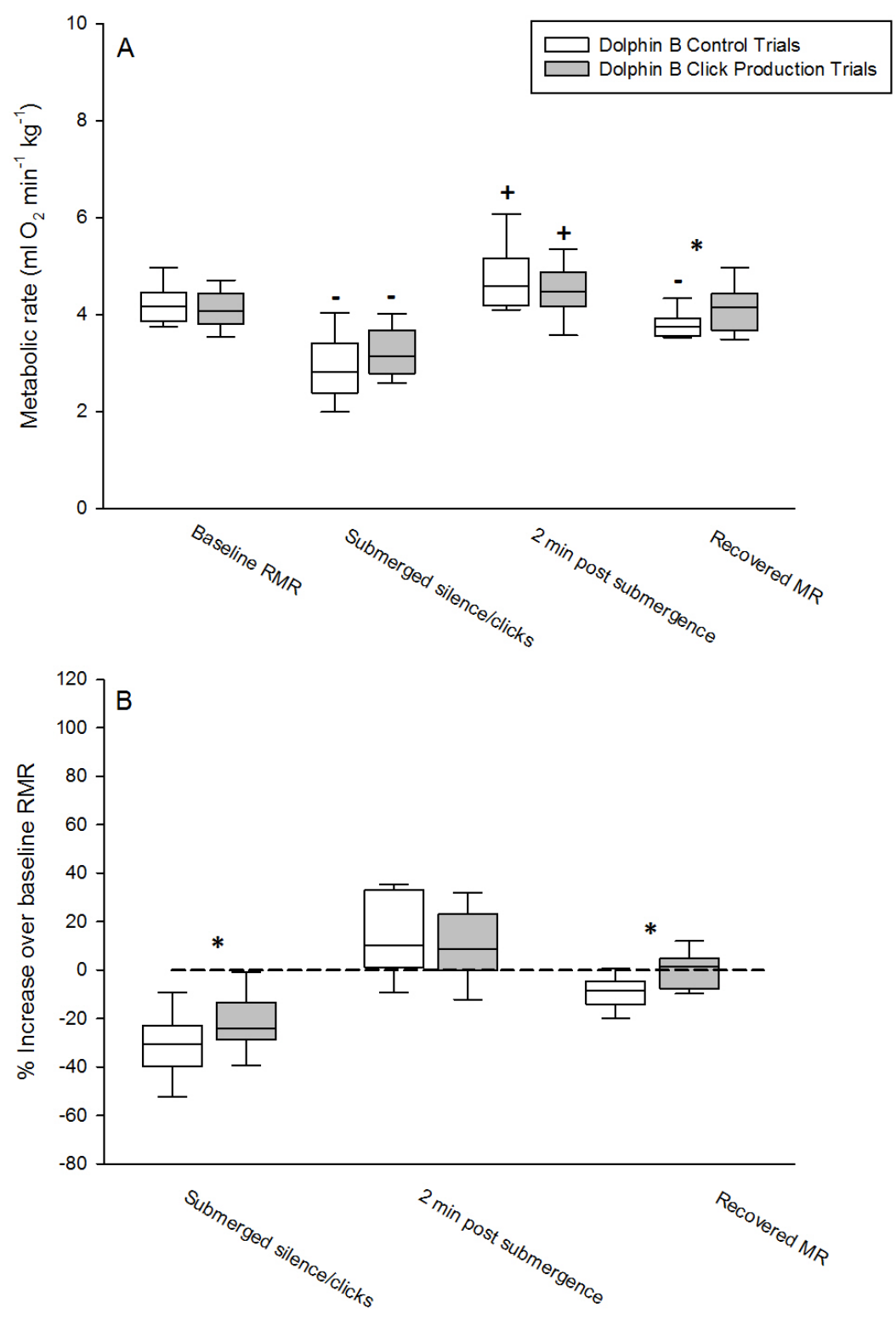

Figure 4. Metabolic rate (A) and percent increase over baseline metabolic rate (B) during components of control and click production trials for Dolphin B. Box plots are presented with white bars representing control (silent) trials and gray bars representing click production trials.

For each box plot, the bottom of the box indicates the 25th percentile, the solid line within the box marks the median, and the top of the box indicates the 75th percentile. Error bars above and below the box indicate the 90th and 10th percentiles, respectively. The trial components are described in the methods. Metabolic rates that are significantly $(P<0.05)$ lower and higher than baseline values within the same trial type are indicated by-and +, respectively. Metabolic rates and percent increase over baseline RMR that differ across trial type (click production or control) for specific trial components are indicated by *. In figure $B$, the dashed line at 0 indicates no change in metabolic rate, relative to baseline. Negative values indicate that the metabolic rate recorded during a trial component was reduced, relative to the baseline value recorded during the same trial. Positive values indicate that the metabolic rate recorded during a trial component was increased, relative to the baseline value recorded during the same trial. 

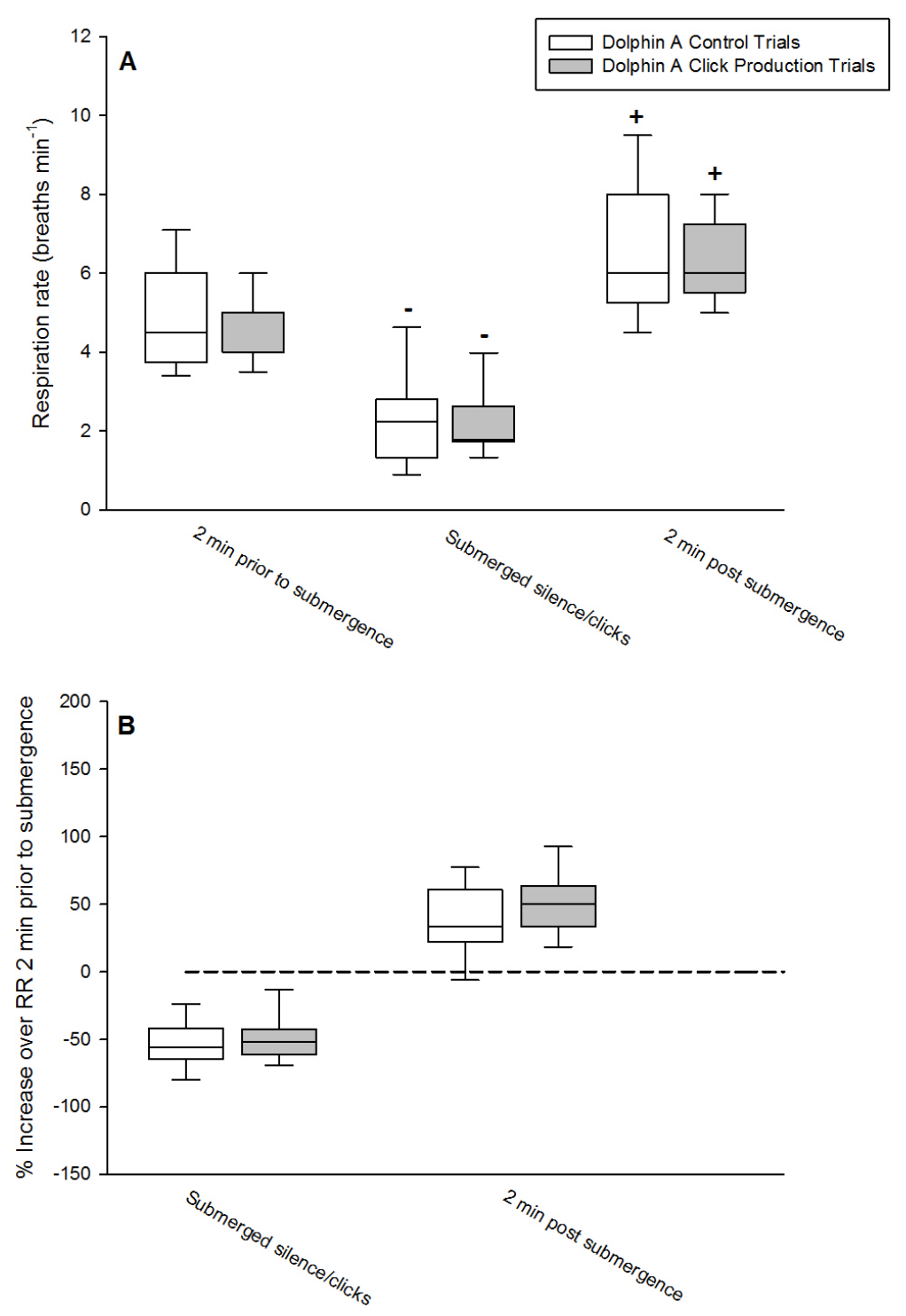

Figure 5. Respiration rate (A) and percent increase over 2 min prior to submergence respiration rate (B) during components of control and click production trials for Dolphin A. Box plots are presented with white bars representing control (silent) trials and gray bars representing click production trials. For each box plot, the bottom of the box indicates the 25th percentile, the solid line within the box marks the median, and the top of the box indicates the 75th percentile. Error bars above and below the box indicate the 90th and 10th percentiles, respectively. The trial components are described in the methods. Respiration rates that are significantly $(P<0.05)$ lower and higher than values 2 min prior to submergence within the same trial type are indicated by - and + , respectively. Respiration rates and percent increase over 2 min prior to submergence respiration rates that differ across trial type (click production or control) for specific trial components are indicated by *. In figure $B$, the dashed line at 0 indicates no change in respiration rate, relative to 2 min prior to submergence. Negative values indicate that the respiration rate recorded during a trial component was reduced, relative to the value recorded during the 2 min prior to submergence in the same trial. Positive values indicate that the respiration rate recorded during a trial component was increased, relative to the baseline value recorded during the 2 min prior to submergence in the same trial. 

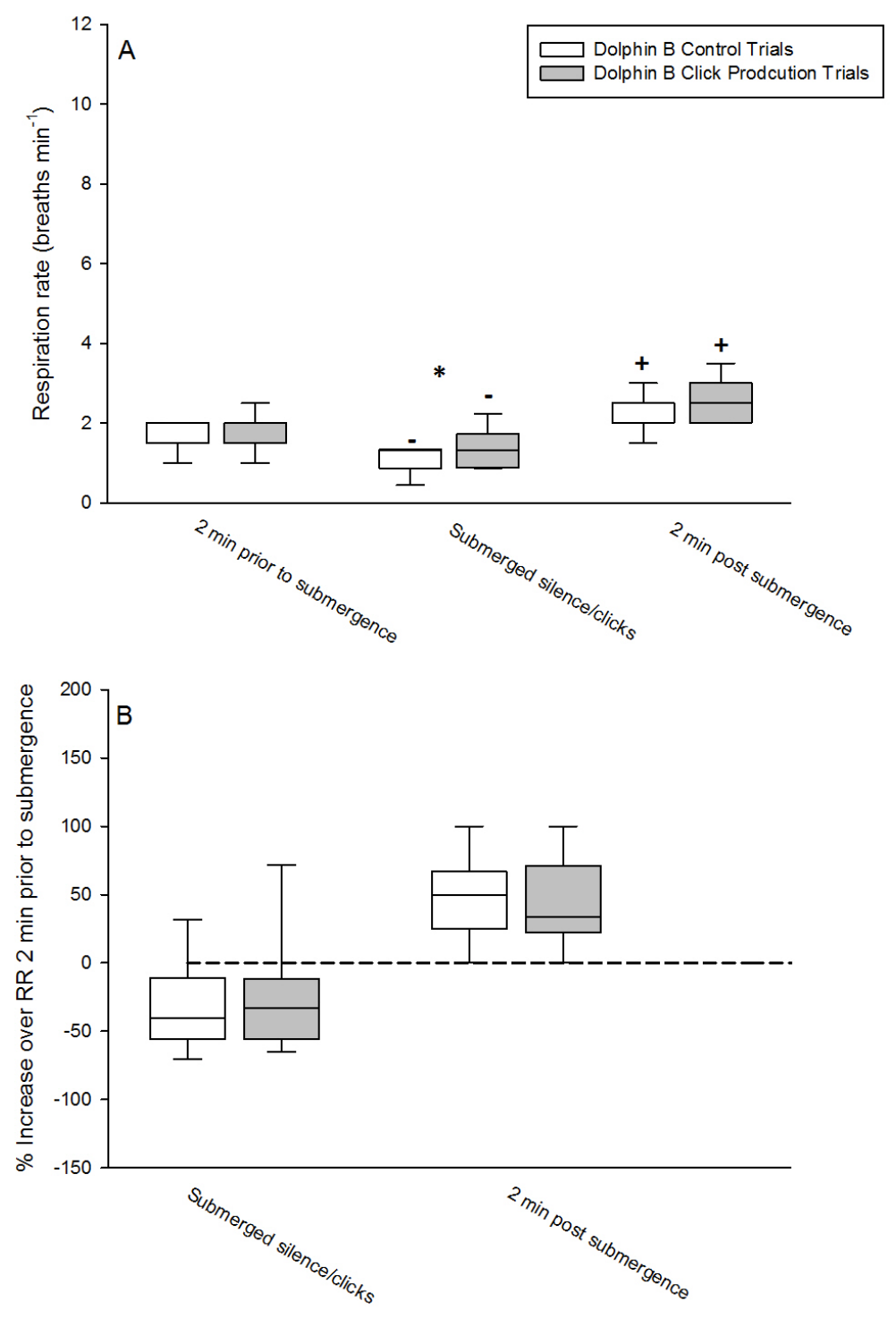

Figure 6. Respiration rate (A) and percent increase over 2 min prior to submergence respiration rate (B) during components of control and click production trials for Dolphin B. Box plots are presented with white bars representing control (silent) trials and gray bars representing click production trials. For each box plot, the bottom of the box indicates the 25th percentile, the solid line within the box marks the median, and the top of the box indicates the 75th percentile. Error

bars above and below the box indicate the 90th and 10th percentiles, respectively. The trial components are described in the methods.

Respiration rates that are significantly $(P<0.05)$ lower and higher than values 2 min prior to submergence within the same trial type are indicated by-and + , respectively. Respiration rates and percent increase over 2 min prior to submergence respiration rates that differ across trial type (click production or control) for specific trial components are indicated by *. In figure $B$, the dashed line at 0 indicates no change in respiration rate, relative to 2 min prior to submergence. Negative values indicate that the respiration rate recorded during a trial component was reduced, relative to the value recorded during the 2 min prior to submergence in the same trial. Positive values indicate that the respiration rate recorded during a trial component was increased, relative to the baseline value recorded during the 2 min prior to submergence in the same trial. 
Metabolic rates during submerged clicking increased linearly with increasing cumulative energy density of all clicks produced per trial (Fig. 7). For both dolphins combined, this relationship was significant $\left(\mathrm{r}^{2}=0.4, \mathrm{~F}=43.0, \mathrm{P}<0.001, \mathrm{n}=54\right)$ and described by the following equation:

$\mathrm{MR}_{\text {submerged click period }}=(0.1 * \mathrm{cEFD})-13.7$

Eq. 2

Where $\mathrm{MR}_{\text {submerged click period }}$ is the mass-specific metabolic rate during the submerged click production bout in $\mathrm{ml} \mathrm{O}_{2} \mathrm{~min}^{-1} \mathrm{~kg}^{-1}$ and cEFD is the cumulative energy flux density in $\mathrm{dB}$ re $1 \mu \mathrm{Pa}^{2} \mathrm{~s}$.

It is important to note that although metabolic rates during click production increase with the cumulative energy level of the clicks produced, the mass-specific metabolic rates of dolphins clicking while submerged fall within the range measured for submerged dolphins that are silent. This again suggests that additional metabolic expenditure due to click production, and even exerting more effort into click production, is somewhat negligible in submerged dolphins.

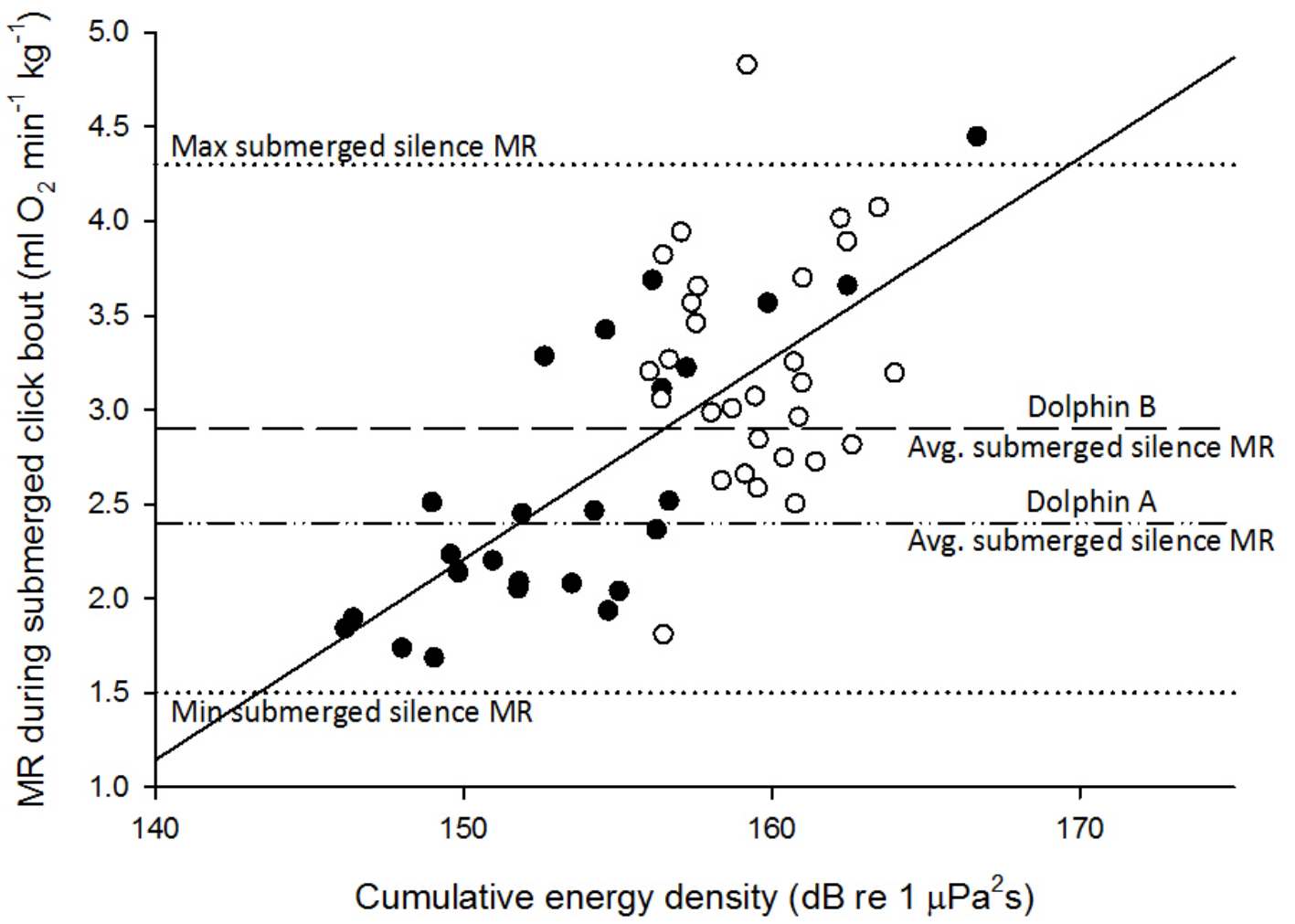

Figure 7. Metabolic rate during submerged click bouts in relation to the cum ulative energy density of all clicks produced during the bouts. Data from Dolphin A (black circles) and Dolphin B (white circles) are combined. The linear regression (solid line, equation and statistical results reported above), minimum and maximum metabolic rates recorded during submerged silence bouts (dotted lines, represents min and max of all trials from both dolphins combined), and the average metabolic rate for submerged silence bouts for Dolphin A (dash-dot-dot line) and Dolphin B (dashed line) are presented for comparison. 


\section{IMPACT/APPLICATIONS}

Empirical data collected from this study illustrate that there is a very small metabolic cost of click production in bottlenose dolphins that is related to the energy content of the signals produced. Overall, the metabolic cost of click production appears to be much smaller than the metabolic cost of communicative signal production, including whistles and squawks, in bottlenose dolphins (Noren et al.2013). Dissimilar to the metabolic cost of producing communicative sounds, the metabolic cost of producing clicks is negligible to the total energetic demands of diving and swimming in dolphins. However, the metabolic cost of producing communicative sounds could also be considered low, relative to the cost of performing other behaviors (Noren et al. 2013). For example, the energetic demand of performing surface active behaviors is substantially greater than the energetic demand of producing both communicative sounds and clicks (Yazdi et al., 1999; D.P.N., unpublished data). Because the cost of click production is related to the energy content of the signal and animals modify their acoustic signals in response to anthropogenic sounds, our results provide important data that can be incorporated in efforts to assess the biological significance of behavioral and acoustic responses to anthropogenic sound exposure.

\section{RELATED PROJECTS}

Dr. Terrie Williams' Marine Mammal Physiology Project involves other studies on the two dolphins used in this study. The goal of one related study is to assess the changing energetic demands in cetaceans, and in particular, determine the principle factors in regulating the variable metabolism of cetaceans over the seasons.

http://www.mmpp.ucsc.edu/The_Marine_Mammal_Physiology_Project/Home.html

\section{REFERENCES}

Au, W.W.L. 1993. The Sonar of Dolphins. Springer, New York.

Au, W.W.L, Floyd, R. W., Haun, J.E. 1978. Propagtion of Atlantic bottlenose dolphin echolocation signals. Journal of Acoustical Society of America 64, 411-422.

Holt, M.M., Noren, D.P., Veirs, V., Emmons, C.K., Veirs, S. 2009. Speaking up: Killer whales (Orcinus orca) increase their call amplitude in response to vessel noise. Journal of the Acoustical Society of America (JASA) Express Letters. 125: EL27-EL32 (Published online 22 Dec 2008).

Holt, M.M., Noren, D.P., Williams, T.M. 2011. Metabolic cost of sound production in dolphins: assessing the energetic impact of vocal compensation in noisy habitats. $19^{\text {th }}$ Biennial Conference on the Biology of Marine Mammals.

Holt, M.M., Noren D.P., Williams, T.M. 2011. Metabolic rates during sound production in bottlenose dolphins (Tursiops truncatus) and evaluating costs of noise-induced vocal compensation. $3^{\text {rd }}$ Symposium on Acoustic Communication by Animals. 1-5 August, Cornell University, Ithaca,

Jacobs, M., Nowacek, D.P., Gerhart, D.J., Cannon, G., Nowicki, S., Forward Jr., R.B. 1993. Seasonal changes in vocalizations during behavior of the Atlantic bottlenose dolphin. Estuaries 16, 341346.

Madsen, P.T., Wahlberg, M. 2007. Recording and quantification of ultrasonic echolocation clicks from free-ranging toothed whales. Deep-Sea Research I 54, 1421-1444. 
National Research Council (NRC). 2003. Ocean Noise and Marine Mammals. National Academy Press, Washington, DC.

National Research Council (NRC). 2005. Marine Mammal Populations and Ocean Noise: Determining When Noise Causes Biologically Significant Effects. National Academy Press, Washington, DC.

Noren, D.P., Holt, M.M., and Williams, T.M. 2011. Assessing long term impacts of vocal compensation to ambient noise by measuring the metabolic cost of sound production in bottlenose dolphins. 161st Meeting of the Acoustical Society of America, 23-27 May. Seattle, WA. Journal of Acoustical Society of America 129: 2397.

Noren, D.P., Holt, M.M., Dunkin, R.C., and Williams, T.M. 2013. The metabolic cost of communicative sound production in bottlenose dolphins (Tursiops truncatus). The Journal of Experimental Biology 216, 1624-1629.

Parks, S.E, Johnson, M., Nowacek, D., Tyack P.L. 2010. Individual right whales call louder in increased environmental noise. Biology Letters published online 7 July 2010 doi: 10.1098/rsbl.2010.0451.

Scheifele, P.M., Andrew, S., Cooper, R.A., Darre, M., Musiek, F.E., Max, L. 2005. Indication of a Lombard vocal response in the St. Lawrence River beluga. Journal of the Acoustical Society of America 117, 1486-1492.

Wahlberg, M., Jensen, F.H., Aguilar Soto, N., Beedholm, K. Bejder, L., Oliveira, C., Rasmussen, M., Simon, M., Villadsgaard, A., Madsen, P.T. 2011. Source parameters of echolocation clicks from wild bottlenose dolphins (Tursiops aduncus and Tursiops truncatus). Journal of the Acoustical Society of America 130, 2263-2274.

Williams, T.M., Friedl, W.A., Haun, J.E. 1993. The physiology of bottlenose dolphins (Tursiops truncatus): Heart rate, metabolic rate and plasma lactate concentration during exercise. Journal of Experimental Biology 179, 31-46.

Yazdi, P., Kilian, A., Culik, B. M. 1999. Energy expenditure of swimming bottlenose dolphins (Tursiops truncatus). Marine Biology 134, 601-607. 